\title{
Process and impact of product data management implementation
}

\author{
P.M. Wognum*
}

Faculty of Business, Public Administration and Technology,

Department of Technology and Organisation,

University of Twente, P.O. Box 217,

7500 AE Enschede, The Netherlands

Fax:+31534892159Ｅ-mail: p.m.wognum@utwente.nl

${ }^{*}$ Corresponding author

\section{I.C. Kerssens-van Drongelen}

Capgemini Consulting Services,

PO Box 2575, 3500 GN, Utrecht, The Netherlands

E-mail: inge.kerssens@capgemini.com

\begin{abstract}
According to the definition of CIMdata, Product Data management (PDM) supports management of both data and the product development process during the total life cycle of the product. However, several problems exist with the adoption and implementation of PDM functionality in organisations. To learn more about the consequences of selecting and implementing PDM functionality, we have performed a survey in Dutch organisations already using PDM functionality. The survey is a step in our research aimed at developing a methodology for selecting and implementing PDM functionality in a specific context.
\end{abstract}

Keywords: product data management; technology implementation.

Reference to this paper should be made as follows: Wognum, P.M. and Kerssens-van Drongelen, I.C. (2005) 'Process and impact of product data management implementation', Int. J. Product Development, Vol. 2, Nos. 1/2, pp.5-23.

Biographical notes: Nel Wognum is an Assistant Professor at the Department of Technology and Organisation in the Faculty of Business, Public Administration and Technology of the University of Twente. She has worked on several aspects of concurrent engineering within and across organisations in the past ten years with an emphasis on alignment between technology and organisation. One of the subjects in this research has been the implementation of enterprise systems. Currently, Dr. Wognum co-ordinates research in the EU-IST project BEST (Better Enterprise SysTem implementation), which is aimed at improving the start-up of enterprise system implementation projects. She is a member of the editorial board of two international journals and is President of ISPE (International Society of Productivity Enhancement).

Inge Kerssens is Principal Consultant at Capgemini Consulting Services in Utrecht, the Netherlands. Before joining Capgemini, she was an Assistant Professor at the Faculty of Business, Public Administration and Technology of the University of Twente. Her research and professional interest is in the 
improvement and control of research and new product development processes. She is the author of several international journal papers on topics such as knowledge management in $R \& D, R \& D$ performance measurement and $R \& D$ profit centres and member of the editorial board of an international journal in this area.

This paper is an extended version of the paper 'Process and impact of Product Data Management implementation' presented at the CE2001 Conference, July 28 - August 1, Anaheim, California, USA (Wognum et al., 2001).

\section{Introduction}

In the past 20 years, product data management (PDM) systems have grown from extensions to CAD systems into an independent phenomenon. Several commercial packages have been developed that consist of many modules. Suppliers of such packages have extensively enlarged upon advantages and possibilities of PDM systems. Many organisations have implemented PDM systems successfully and with great advantage. Nevertheless, many stories are told about failed implementation and sub-optimal use. Besides technical problems, organisational problems play a large part in these stories.

Product data management systems are systems that concern many functions in an organisation. They connect functions, departments, and even organisations. PDM systems can, therefore, be considered as enterprise-wide systems, the so-called enterprise systems (ES). Enterprise resource planning systems (ERP) form a comparable category of ES. The question can even be posed whether PDM systems should be considered as an extension to ERP or vice versa. In this paper, we will not concern ourselves with this question. Our focus will be the process and impact of implementing a PDM system.

It is known that implementation of a new technology has a large impact, both technical and organisational (Boer, 1991; Krabbendam, 1988). Implementation of a new technology and especially an enterprise-wide system like PDM involves large organisational change (Davenport, 2000). For example, people in the organisation have to learn to work in a different way, functions change, control and management of the primary process change, standards disappear or have to be adapted drastically, and relationships with clients and suppliers alter. These changes are not always anticipated (Davenport, 2000; Markus and Tanis, 2000) or are unintended consequences of the way technology is used (Orlikowski, 1992).

Knowledge of the causes of success and failure of PDM implementation efforts will help to improve and support current and future PDM implementation processes. Such knowledge is still fragmental, incomplete, or not widely accessible. In this paper, we present results of an initial step in our research into building a methodology for selecting and implementing PDM systems. This step consists of a survey on the current situation with respect to implementation and impact of PDM systems in Dutch industries.

Below, in Section 2, we will sketch the background of our research. In Section 3, our research approach and design of the survey are briefly described. We introduce the PDM functionality considered in our survey. The functionality is based on the CIMdata (1995) definition of PDM. In Section 4, we present the results of our study. In Section 5, we will 
compare our results with other recent investigations into the status of PDM implementation and the process of implementing enterprise systems. In Section 6, we will reflect on the results and present an outline of a methodology that will support organisations in tracking and improving the PDM implementation process. We end this paper with conclusions.

\section{Background of the research}

As already mentioned in the introduction, several problems exist with the adoption and implementation of PDM functionality in an organisation. There have been many studies on the implementation of new technology in organisations, e.g., the introduction of enterprise systems (Davenport, 2000; Markus and Tanis, 2000), flexible manufacturing systems (Boer, 1991; Krabbendam, 1988) and information systems (Davenport, 2000; Orlikowski, 1992). The process of implementing a new technology like a PDM system is full of pitfalls. A long history of recurring problems can be found in the literature (Kwon and Zmud, 1987; Nash, 2000; Landauer, 1995; Willcocks and Lester, 1999). In addition, many guidelines exist for implementing changes in an organisation (see e.g., During, 1986). However, despite the knowledge gained in theory and practice, many change processes still lead to unexpected consequences, many of which are undesired. Consequently, many projects fail to achieve the anticipated benefits (KPMG, 2002).

The reasons for the problems encountered in implementing new technology like PDM in an organisation may be found in the complexity of the implementation process. In particular, the general nature of PDM functionality makes it difficult for organisations to decide on which specific functions to select. This choice depends on the specific context, like the organisation's strategy, market and products, organisational structure and culture, and the technology already in use. In addition, PDM functionality can be implemented in many different ways with a variety of (combinations of) systems and tools. Existing technology in the organisation, like CAD systems and ERP, could be extended with PDM functionality, while new technology may have to be integrated with technology already in use. Like any other technology, implementing PDM functionality impacts the way of working in an organisation including people's roles, responsibilities, and authorities, may create new possibilities, or may lead to undesired outcomes. Such impact is often underestimated despite the experience with many earlier introductions of new technology (Boer, 1991; Trist and Bamford, 1951; Ruël, 2001). Technical problems account for less than $10 \%$ of the problems, while the remaining $90 \%$ are mainly human and organisational in nature (Bikson and Gutek, 1984).

Introducing new technology requires many contingencies to be taken into account, such as organisational strategy, market and products, organisational size, technology already in use, organisational structure and culture (see e.g., Boer 1991; During 1986), and, to an increasing extent, relationships and collaboration with clients or suppliers (Wognum and Faber, 2002; Wognum et al., 2001). Moreover, an implementation process is often very different from the daily routines in an organisation. An implementation process is mostly performed in a project, which needs an organisation that may be different from the daily way of working in the permanent organisation (Lange-Ros de, 1999), while the time lag between such projects may be very large. In addition, active managerial and organisational support is needed to facilitate and guide 
the implementation process. General implementation guidelines, as can be found in the literature, may not be sufficient to decide on the specific support needed.

In our research, we aim at identifying the problems encountered in selecting and implementing PDM functionality. Our goal is to develop implementation guidelines that supplement existing guidelines to support PDM implementation, especially from a managerial and organisational point of view. We will specifically adopt a learning approach to implementation based on a continuous cycle of evaluation and improvement (see also Section 6). Specific performance indicators need to be developed for this purpose (Kerssens-van, 1999).

\title{
3 Research approach
}

The research presented in this paper can be characterised as descriptive and explorative. Our goal is to learn more about the consequences of selecting and implementing PDM functionality in an organisation. To achieve this goal, we have performed a survey in Dutch organisations that have already implemented a PDM system as well as in consultancy organisations that have assisted in selecting and implementing PDM functionality. A survey is applicable for performing explorative research (Yin, 1994). It is a cross-case technique aimed at answering 'what', 'who' and 'how many' questions, but cannot be used to answer 'why' and 'how' questions. We have chosen this instrument for a first exploration of the field and to identify potentially interesting companies for further research using a more in-depth methodology like case studies to obtain answers to why and how questions (Yin, 1994).

The survey has been designed based on the CIMdata definition of PDM. According to the definition of CIMdata

\begin{abstract}
"Product Data Management (PDM) is a tool that helps engineers and others manage both data and the product development process. PDM systems keep track of the masses of data and information required to design, manufacture or build, and then to support and maintain products." (CIMdata, 1995)
\end{abstract}

PDM is a function that generalises techniques, which are known as engineering data management (EDM), document management, product information management (PIM), technical data management (TDM), image management, and other names (CIMdata, 1995).

According to the functions defined by CIMdata, we have compiled the following list of user functions:

- data vault and document management

- change management

- $\quad$ workflow and process management

- $\quad$ product structure management

- configuration management

- parts' management

- $\quad$ project and programme management. 
In addition, several utility functions have been defined to support and facilitate the use of a PDM system. These functions interface with the operating environment and shield this environment from the user. The functions are:

- communication support

- data transport

- data translation

- $\quad$ image services

- administrative functions.

We have divided the survey questions, which were predominantly closed questions, into three categories. The first category of questions is aimed to characterise the organisations involved. The second category of questions addresses the current status of the PDM system in use. Answers to these questions are expected to provide us with insight into the extent of the implementation, like the functionality implemented, departments and organisations involved, and the phase of the implementation process. The third category of questions addresses the implementation process itself. Several aspects are included like the reasons for implementing a PDM system, system choice, time span of implementation, approach chosen, parties involved, earlier attempts, changes in the organisation and, especially, differences between expected and realised advantages and between expected problems and problems that really occurred.

\section{Survey results}

From all questionnaires received, we selected responses only from those organisations that really have implemented PDM. After selection, the total number of questionnaires used in our survey is 10 . Because of this number, quantitative analysis was not possible. However, the results give us an indication of the current status of PDM implementation and impact and will lead to additional research questions.

The respondents comprise two external suppliers of PDM systems, four internal system developers, and four end users. More than one respondent in one organisation could answer the questionnaire. This happened in only one organisation, where two internal system developers and one end user answered the survey questions. Therefore, our survey is based on the situation of PDM implementation in eight organisations.

Below, we will present our results. Answers to each category of questions will be discussed in separate sub-sections.

\subsection{Company characteristics}

All organisations can be characterised as configure-to-order, engineer-to-order, or design-to-order. Two organisations have also batch processes. Seven organisations are industrial companies in different areas, such as aerospace, defence, machining, and metal. The eighth company operates in the building industry.

The size of the companies varies from small $(n=2)$ with 100-500 employees, through middle-sized $(n=5)$ with 500-2500 employees, to large $(n=1)$ with over 2,500 employees. Turnover varies from 10 million to more than one billion. The size of the 
$R \& D$ department is not proportional to the size of the company. Half of the companies have R\&D departments with 100-200 employees. Three companies have smaller R\&D departments, while one company has an R\&D department with more than 500 employees.

\subsection{Status of the PDM system}

In this section, the current status of PDM implementation will be discussed.

\subsubsection{Implementation of PDM functions}

Two companies have more than 10 years of experience with one or more PDM functions. These functions are change management, product structure management, configuration management, parts' management, and project and programme management. These two companies have developed most applications in-house. These early attempts have not led to an integral system. On the contrary, integration of the different functions is less than optimal. At this point in time, not all of these functions are really used.

Since 1994, the companies that participated in our research started using commercial packages like Sherpa, Cadim, Pafec, and Metaphase. Quintus, Iman, and PIMS are also mentioned in this context. Table 1 shows those PDM functions that have been implemented in the respective packages.

Table 1 Functions implemented in commercial packages

\begin{tabular}{lllllllllllll}
\hline & 1 & 2 & 3 & 4 & 5 & 6 & 7 & 8 & 9 & 10 & 11 & 12 \\
\hline Sherpa & $\mathrm{X}$ & & $\mathrm{X}$ & $\mathrm{X}$ & $\mathrm{X}$ & $\mathrm{X}$ & & & & & $\mathrm{X}$ & $\mathrm{X}$ \\
Cadim & $\mathrm{X}$ & $\mathrm{X}$ & & $\mathrm{X}$ & & $\mathrm{X}$ & & & & $\mathrm{X}$ & & \\
Pafec & $\mathrm{X}$ & & & & & & & & & & & \\
Metaph & $\mathrm{X}$ & $\mathrm{X}$ & $\mathrm{X}$ & $\mathrm{X}$ & $\mathrm{X}$ & & $\mathrm{X}$ & & $\mathrm{X}$ & & $\mathrm{X}$ & $\mathrm{X}$ \\
SAP & & & & & $\mathrm{X}$ & & $\mathrm{X}$ & & & & & $\mathrm{X}$ \\
\hline
\end{tabular}

1: data vault and document management; 2 : change management; 3 : workflow and process management; 4: product structure management; 5: configuration management; 6: parts' management; 7: project and programme management; 8: communication support; 9: data transport; 10: data translation; 11: image services; 12: administrative functions.

In general, people in the respective companies are rather satisfied about the systems implemented so far. Satisfaction with in-house developed applications is lower compared to satisfaction with commercial applications.

From all the PDM functions, data vault and document management is the most widely implemented function. This function has been implemented in all companies. This function is followed by product structure management $(n=7)$, parts' management $(n=6)$, and image services $(n=7)$. Configuration management $(n=5)$, data transport $(n=5)$, and administrative functions $(n=5)$ are considered central by many organisations since a long time already, but are not fully integrated yet in enterprise-wide implementation. The need for change management $(n=5)$ is growing considering the short-term plans for implementing this function. Workflow and process management $(n=2)$ and project and programme management $(n=4)$ do not yet receive full attention. 


\subsubsection{PDMfunction usage}

In Figure 1, the use of a PDM system by different departments is depicted. The figure shows that $\mathrm{R} \& \mathrm{D}$ /product development $(28 \%)$, production engineering $(23 \%)$, and production $(20 \%)$ are most often mentioned when looking at the different companies and the different user functions. Purchase (14\%) follows these departments closely, while maintenance and service (11\%) also start to take their share in using PDM, but still for a limited number of functions and a very few companies. Marketing and sales (4\%) make still limited use of PDM. Automation and network control do not use the PDM user functions.

Figure 1 PDM system usage by the different departments $(n=124)$
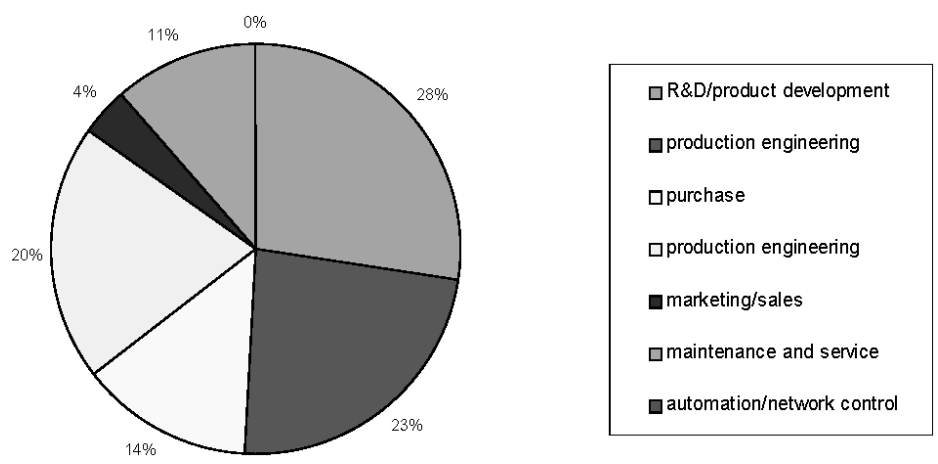

While Figure 1 shows the level of involvement of the various departments in PDM system usage, Figure 2 shows the relative use of the PDM user functions. Figure 2 shows that data vault and document management (28\%) take the largest share in PDM function usage, followed by product structure management (17\%), change management $(17 \%)$, configuration management $(15 \%)$, and parts' management $(11 \%)$. The functions workflow and process management $(9 \%)$ and project and programme management $(3 \%)$ are not yet used extensively.

Figure 2 Relative use of PDM functions $(n=124)$
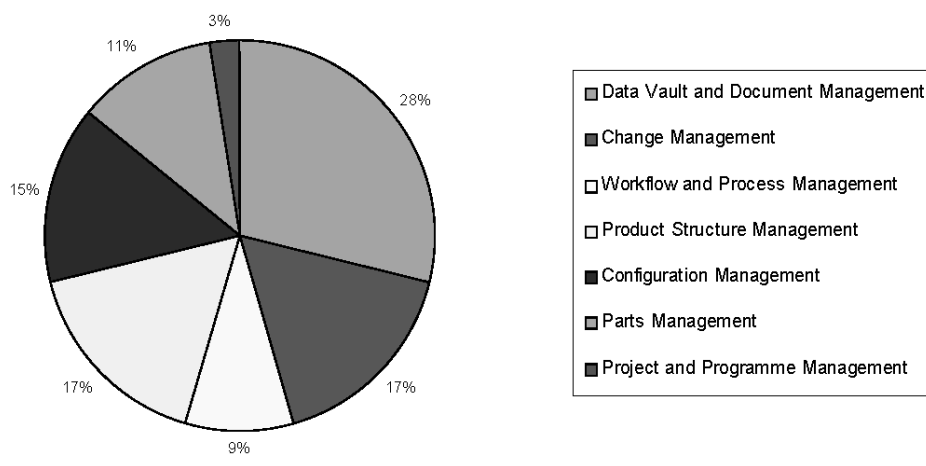

Figure 3 shows the usage of the different PDM user functions by the various departments. In interpreting the results, we have to take into account the size of our survey as well as the preliminary status of PDM as an enterprise-wide system. 
Based on Figure 3, the following conclusions can be drawn:

- Data vault and document management are predominantly used by R\&D/product development, production engineering and, to a lesser extent, production. In less than half of the companies investigated, this function is also used by purchase, maintenance and service and by marketing/sales.

- Change management follows a similar pattern as data vault and document management, but for fewer companies. Marketing/sales are not using this function.

- Workflow and process management are not widely used, but seems primarily important for R\&D/product development, production engineering and production. Purchase, marketing/sales and maintenance/service are not heavily involved in process management yet.

- Product structure management is primarily used by $\mathrm{R} \& \mathrm{D}$ /product development, production engineering, purchase, and production. Maintenance/service are using this function in three companies, while marketing/sales are involved in only one company.

- Configuration management does not yet play a large part. This function is important to production at this point in time, followed by production engineering, $\mathrm{R} \& \mathrm{D} /$ product development and maintenance and service. Marketing/sales are not using this function.

- Parts' management is mostly used by R\&D/product development. In a few companies, production engineering, purchase and production also use this function.

- Project and programme management are only used by $\mathrm{R} \& \mathrm{D} /$ product development and by maintenance/ service in only two companies.

Figure 3 PDM function usage per department

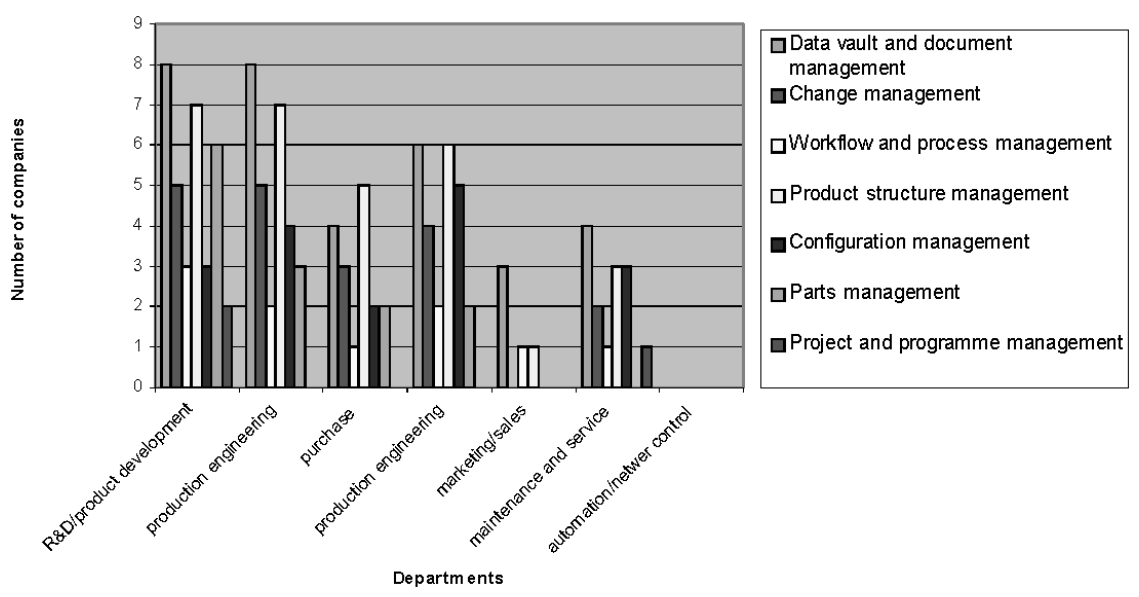

In summary, PDM systems are mainly used in the product creation process. The upstream and downstream processes like marketing/sales and maintenance/service are currently involved to a limited extent through PDM system use. PDM systems are starting to have an enterprise-wide character, although there is still a long way to go. Integration between 
PDM functions is not yet optimal, there is still a hotchpotch of different applications, and configuration of PDM systems in and the usage by the different departments can considerably vary within one company.

\subsubsection{System integration}

In all companies, PDM systems are integrated with CAD systems. In one company this is, however, only the case for parts' management. In six companies, the PDM system is also partly coupled with an ERP system. Some respondents mention coupling with document management, MRP, hour registration, a second configuration management system with logistics management system, drawing registration, and distribution.

These findings confirm the picture that current PDM systems in most cases do not yet satisfy the enterprise-wide character these systems are supposed to have. The focus is primarily on the design and engineering process and to a lesser extent on the production process. Only parts of the PDM system are coupled with ERP systems.

\subsubsection{Infrastructure}

Different departments make use of the PDM system. It is therefore interesting to know how many connections are realised in the different departments. This question can only be answered by three respondents, all end users. The findings suggest that $R \& D / p r o d u c t$ development and production have the largest number of connections to the PDM system, followed by production engineering and maintenance/service. Automation and network control, marketing/sales, and purchase have a very limited number of connections.

In half of the companies, network connections exist with suppliers and customers. In two of these companies, suppliers and customers incidentally use data vault and document management through the network. In the two other companies, data vault and document management and parts' management are used more regularly, while in one of them change management and product structure management are also used.

The exchange of information with clients and suppliers is still limited as can be concluded from our findings. One of the companies indicated that exchange of information with clients and suppliers is highly necessary for survival. It seems that, unless this necessity is felt, extension of PDM implementation to clients and supplier is not yet pressing for the companies involved.

\subsection{PDM implementation process}

In this section, we will discuss the PDM implementation process. Discrepancies especially between expectations and outcomes will be identified.

\subsubsection{Implementation preparation}

The reasons for implementing PDM were uniform for all companies. All companies expect to achieve advantages for the own organisation by implementing PDM functionality. Other reasons mentioned are that the system should match the PDM systems of clients as well as existing standards.

With respect to package choice, different criteria are mentioned. In three companies, the criteria have been defined externally by the mother company, clients, and partner 
companies, respectively. Furthermore, two companies mention integration with their CAD and ERP systems as a very important criterion. Other criteria for the choice of a system package are:

- the package must be enterprise-wide

- it must enable connection with other systems

- it must fit the underlying it infrastructure

- it should facilitate and support control and diffusion of engineering data

- it should allow fast implementation

- it should need little customisation

- it must be upgradable.

These criteria depend of course on the specific situation in which the PDM system is implemented.

In five companies, a cost/benefit analysis has been performed. In the remaining three companies, such an analysis has not been made. In one of those companies, the respondent indicates that such an analysis should have been performed, because the project has come to a dead end.

\subsubsection{Implementation process}

Although in terms of the number of person months the length of the implementation process can be considered as reasonable, a number of problems have been mentioned:

- The PDM implementation has been successful for only a part of the PDM functionality. The rest will not be implemented most probably.

- The first attempt has not led to an operational system due to continuous changes and an inflexible system.

- After implementation, it took a long time before end users considered the system as stable.

For most companies that participated in the survey, implementation of PDM is a first attempt. Only two companies have undertaken an earlier attempt. Three companies do have experience with PDM development and implementation activities for ten years and more. At this point in time, parts of the old systems are renewed or replaced.

In three companies, a pilot project has preceded full PDM implementation. In one company, the process proceeded according to a well-defined plan. In three companies, there has been a plan, but the process was frequently adapted due to changing requirements and wishes. In one company, this way of working has caused frequent shifts in the project focus, leading to extensive delay.

During the implementation process, various departments and parties have been involved. Figure 4 shows the relative involvement of those parties. Based on our findings we can conclude that automation and network control $(14 \%)$ are involved in the implementation process to the same extent as external advisors (14\%). Of all departments that play a role in the product development process, production engineering $(21 \%)$ is most involved in the implementation process. R\&D/product development (14\%) follows 
closely, while production (7\%), purchase (4\%), marketing/sales (4\%), and maintenance/service (4\%) have a limited share in the implementation process. The involvement of general management is limited to $11 \%$. Important suppliers (7\%) do play their part when needed apparently, while there is no response mentioning the involvement of important clients.

Since the number of respondents in our survey is rather limited, the distribution of parties involved in the implementation process as presented above only gives an indication of the extent of involvement. We can conclude however that the implementation process is still mainly focused on the own company, in particular the engineering process. The enterprise-wide character of PDM is recognised, but not yet visible in an enterprise-wide or even chain-wide involvement.

Figure 4 Involvement of departments and other parties in the implementation process

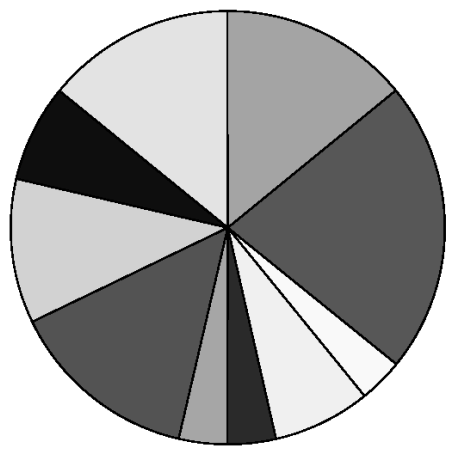

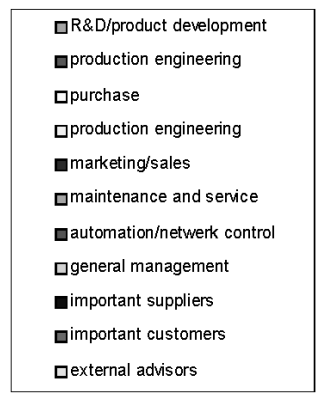

\subsubsection{Expected and realised advantages}

Several positive effects have been expected from implementing a PDM system. Strong positive effects have been expected, for example, with respect to cost reduction in product development and production/assembly. These expectations are met for the production/assembly process, while cost reductions in product development are lower than expected. Expectations have not been very high with respect to cost reductions in purchase and service/maintenance processes. Effects on cost reduction in these processes are not or barely observed, except for large cost reduction in service/maintenance in one company.

Expectations with respect to reduction in time-to-market of new products have been reasonably large. In most companies these expectations are met, although to a lesser extent than expected. Effects on throughput time reduction of the production/assembly process are also less than expected, while reduction in throughput time in service/maintenance is neither observed nor expected.

Expectations with respect to reduction in the number of design changes, during the design process, after release of the product for production/assembly, and after commercial release, have been moderate. These expectations are partly met. On the other hand, expectations with respect to reuse of product parts as well as reduction in the number of parts have been high. In most companies these expectations are met, although effects are smaller than expected.

Collaboration between disciplines is improved in most companies, although the effect on collaboration is less strong than expected. Improvement in the collaboration with 
clients and suppliers can hardly be observed, while expectations with respect to improvements in such collaboration have been moderate.

While expectations with respect to higher customer satisfaction on the product have been moderate, effects can hardly be observed. With respect to customer satisfaction on order processing and service/maintenance, expectations have been very low. These expectations are not surpassed.

Finally, one company has noted that introduction of a PDM system has led to less internal administration and better quality management.

Overall, we may conclude that on average the implementation of PDM has generated considerable benefits, but that the expectations were even higher.

\subsubsection{Expected and experienced problems}

Many problems have been expected with respect to coupling of a PDM system with existing systems and the conversion of data. In fact, companies have encountered more problems with system coupling than with data conversion. It is interesting to note that for those companies that have anticipated on these technical difficulties, problems have been less severe, while problems have been quite extensive for companies that have not expected large technical problems.

More problems have been expected with definition of functional and technical requirements than with modelling the business processes. These expectations have been met indeed. More research is needed to determine to what extent the specific selection of PDM functionality influences the occurrence of these problems.

Problems have been expected with respect to collaboration between the different parties involved in the implementation process, especially management and relevant parties within the organisation. In those companies that have expected them, these problems have been observed. No problems have been observed in the two companies that have not expected such problems. The question rises whether problems have been prevented because of a good change management approach or just good luck. In other cases, the selection of specific PDM functionality could have influenced the need for extensive collaboration between the relevant parties.

Although problems with respect to collaboration with clients and suppliers have been expected, these problems have turned out smaller than expected. It could be that their involvement has been limited, but further research is needed to find explanations for this observation. Moreover, conclusions with respect to support by PDM system suppliers cannot be drawn. In some companies, problems with this party have been rather severe, whether expected or not, while in other companies problems in this area could hardly be observed.

For a PDM system implementation to succeed, end users must have a collaborative attitude and a sufficient level of knowledge and skills for using the system. Internal and external system developers have expected as well as observed problems with respect to this point. Two out of the four end users have expected problems, while for one of them problems have not been observed. In three companies, problems have been observed.

Maintenance of the PDM system has appeared to present larger problems than expected. This point requires also further investigation.

Time and budget allocated to the PDM system implementation have shown to be insufficient, although not always expected beforehand. In six companies, time planned for technical realisation has appeared to be far too short, while in all companies time 
allocated for training and organisational embedding of the system has been exceeded substantially. One respondent noted that problems have been caused by instability of the IT systems involved.

\subsection{Summary}

Results of the survey show that both technical and organisational problems have been encountered during PDM system implementation. These problems have not always been expected or anticipated. Moreover, although benefits can be observed from implementing a PDM system, more research is needed to determine which benefits can be expected as well as which conditions favour these benefits.

\section{Comparison with other research}

Two investigations have been performed that can be compared with our survey. The first one (R1) is a benchmark research at Ruhr University, Bochum, in cooperation with IBM and CIMdata (Engineering Data Management Newsletter, 1999). R1 consisted of an international survey comprising 100 managers of 33 medium-sized to large companies, mainly in the automotive and aerospace industry, with more than 15 years of experience with EDM/PDM systems. Based on the results, the companies have been divided into two groups: early adopters and followers.

The second investigation (R2) is a survey performed in the United Kingdom in more than 100 middle-sized and large leading companies in manufacturing and engineering (Engineering Data Management Newsletter, 2000). The survey is aimed to support companies still doubting the value of PDM. The potential of PDM is not fully realised however. In $65 \%$ of the companies investigated, PDM has been implemented compared to $42 \%$ in 1995 . Adoption of EDM has not changed in essence. The results discussed concern only those companies that have implemented PDM.

Only $15 \%$ of the early adopters in R1 have achieved the highest reported level of system use and integration. In general, the level of application and integration is not yet very high. In R2, the companies investigated appeared to belong to the early adopters. Eighty nine percent of these companies have applied PDM primarily to solve problems in managing $\mathrm{CAD}$ files. Configuration management, a function strongly related to CAD management, has been implemented in $49 \%$ of the companies. In $17 \%$ of the companies, the PDM system is used to manage other engineering files like digital documents or spreadsheets. In $14 \%$ of the companies, full text retrieval is possible, especially in companies that have implemented EDM.

Results of R1 show that companies efficiently managing their product data have achieved competitive advantage, while this advantage is considerably less for those companies that have not systematically invested in EDM/PDM systems. In addition, product development appears to be more successful for early adopters especially because of higher productivity and better communication between engineers. Also, lower costs of product development and better reuse of components are reported. Results of R2 show that in $89 \%$ of the companies, PDM systems have led to advantages and a good ROI. For those companies in which this is not the case, the reason might be the use of several different older systems ( $>5$ years). In $55 \%$ of the companies, PDM has delivered the 
advantages expected, although PDM implementation is often still at the initial stage of a more encompassing implementation.

Results of R2 also show that the large advantages expected from effective management and communication of engineering data in the extended enterprise cannot yet be realised by the early adopters. Department-oriented budgets often complicate system implementation across departmental and even organisational borders. Management support is essential to implement PDM enterprise-wide and even chain-wide.

Reasons for implementing PDM, mentioned in R1, are mainly operational. Implementation of PDM often proceeds parallel to a BPR process. Process improvement often proceeds after implementation of a PDM system. Opposite to the followers, early adopters were often already involved in process improvement before PDM implementation. Important reasons for implementing PDM mentioned in R2 are access to engineering data $(85 \%)$, workflow, although this function has often not been implemented except for very simple sub-processes, and configuration management $(70 \%)$. This last function is gaining importance fast since companies increasingly adopt mass customisation as well as customer orientation and care. Other reasons are improvement of the engineering process and distribution of engineering data across a larger part of the organisation. In the UK, $74 \%$ of the companies investigated intend to extend PDM implementation to cover the whole organisation, although the time scale for realising this is not yet clear. Web technology is mentioned as a strategic factor to implement PDM chain-wide. In many cases the required infrastructure is already present.

Although results of R1 show that all functions and application areas have been represented in project teams, the focus of the research is especially engineering. The steering board consisted of top management and external partners. The results show that early adopters have invested more money, but have achieved the goals in time (on average 31 months). Followers have invested money according to budget, but have spent considerably more time (on average 45 months). Early adopters have invested more time in the initial phases leading to more efficient implementation and introduction. Because success of EDM/PDM systems depends on user acceptance, early adopters have spent more time and money to education and training. As a result, $66 \%$ of the engineers use the system against $48 \%$ of the engineers in followers. Results of R2 show that $30 \%$ have exceeded budget and $40 \%$ have needed more time. For most companies, the implementation has been the first attempt. Each following attempt is expected to be more efficient by the building of knowledge and experience. Support by an independent $\mathrm{PDM} / \mathrm{EDM}$ consultant is considered useful. While the first attempts have required much time and effort (on average six years), the average implementation process now lasts one, seven years for the newer systems. Of all companies $87 \%$ think that PDM should be implemented before an ERP system. However, ERP is often already present.

Both investigations confirm and complement the picture as presented by our survey. Although many companies have started to build experience with (successful) implementation and use of a PDM system, implementation is often still restricted to a limited number of functions and to a part of the organisation. Our research shows in addition that implementations that incorporate clients and suppliers are only undertaken when pressure is high. Our study also shows the extent to which the organisation as well as clients and suppliers have been involved in implementing PDM and the extent to which the different parties use the different PDM functions. 


\section{Towards an implementation methodology}

Because of the size and impact of implementing PDM in an organisation, the process of implementation must be planned carefully. However, at the start of an implementation process, information and knowledge might be limited, especially when the implementation is a first attempt.

More informed planning of a PDM implementation is possible when experience grows. Moreover, during implementation the situation might change, possibly leading to adaptation of the implementation process. As demonstrated in our survey, in several PDM system implementation processes, the focus has changed several times. This situation favours a learning, evolutionary, or cyclic approach. In Figure 5, we present a model of such an approach. In larger organisations, this approach could first be applied to a pilot, before a broader implementation is contemplated.

Figure 5 A learning approach towards PDM implementation

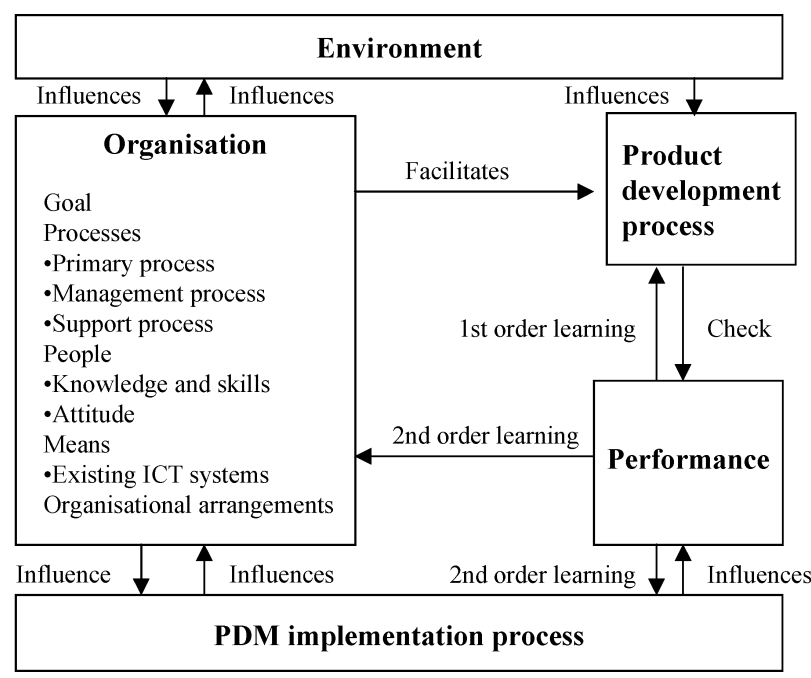

In the model, several interacting elements can be distinguished. First of all, we mention the organisation in which a PDM system has to be implemented. This organisation might be a business unit, a whole company, or a chain or network of companies. The organisation influences and is influence by its environment, since it reacts to and satisfies needs and constraints in the environment. For example, the development of new technology or changes in competitive pressure will influence the decisions in an organisation. The environment might be the mother organisation as well as the market for a business unit or the user market for a company or network.

The organisation has knowledge and skills, so-called competencies (Hamel and Prahalad, 1994), embedded in its goals, processes, people, means (including the PDM system in its current status) and organisational arrangements (Wognum and Faber, 2002). These competencies, especially the business goals, determine the goal of the PDM system implementation process. The implementation process must satisfy (measurable) business goals in terms of time, money or quality. Therefore, a PDM implementation process has to be considered as a business change 
process (Davenport, 2000) in which technology and organisation co-develop (Leonard-Barton, 1988). As such, the PDM implementation process also influences the organisational competencies. We illustrate this reciprocal relationship with some examples:

- Business goals influence the choices to be made with respect to PDM functionality to choose.

- The nature of the product development processes undertaken normally, like market or technological uncertainty, is important in deciding the degree of flexibility needed for a PDM system.

- Reward systems may help to increase commitment of people involved in PDM implementation.

- Financial incentives may provide a positive stimulus.

- Management involvement influences the way implementation proceeds.

For example, active leadership might lead to better results than merely output control.

- Knowledge, skills, attitude, and commitment of people are highly influential factors.

- Current ICT systems and infrastructure influence choices to be made with respect to PDM technology.

- Structure and culture of an organisation, visible in e.g., hierarchy, department structure, geographical dispersion, roles, or the way of working, have to be taken into account in deciding on what PDM functionality to choose and how to implement the system.

Organisational competencies, including the (growing) PDM system, facilitate and influence the business processes. With respect to PDM implementation, the business process focused on is the product development process. This process encompasses all activities in the product lifecycle that are considered to be positively affected by a PDM implementation.

The performance of the product development process can be measured by means of performance indicators, like costs of the various steps of the product life cycle of a single product and/or a product family, throughput times of these product life cycle steps, reduction of parts, reuse of parts, time spent on rework, percentage of projects resulting in a successful product, technical and economical product life, fault free product life, customer satisfaction, time to money, (expected) discounted net cash flow generated by a product, etc. The selection of suitable indicators depends on the goal of the implementation, the characteristics of the process as well as its phase (Kerssens-van, 1999). Moreover, the PDM implementation process itself also influences performance. The results of measurement may require decisions on adaptations to the product development process (1st order learning), adaptations to the organisational competencies, including the PDM system (2nd order learning), or adaptations to the PDM implementation process (2nd order learning) in accordance with the, possibly changed, competencies. The organisation will learn by recurrently applying this cycle of measurement and improvement (Argyris and Schön, 1978). 
This still rather general approach requires instantiation and refinement for specific situations. Such refinement will be different for each situation. In using this approach, each organisation or network of organisations will develop its own specific knowledge and, consequently, adapt the approach to its own circumstances.

In the approach presented here, the well-known continuous improvement Shewhart-Deming plan-do-check-act cycle for Total Quality Management can be recognised (Crosby, 1979) (see also Wognum and Faber, 2002). Our approach offers a systematic holistic approach to view important factors in planning and evaluating an ongoing PDM implementation process from start to end and even after that. It offers a basis for discussion and refinement in specific situations. Moreover, it supports research across several implementation processes. Studying different situations will lead to more general guidelines in adapting and using the model.

\section{Conclusions and further research}

In this paper, results have been presented of a survey into the current status of PDM implementation in Dutch industrial companies. Technical as well as organisational problems have been found in implementing PDM. The findings with respect to adoption, implementation and use of PDM systems in organisations are confirmed by other investigations elsewhere in Europe, in particular with respect to the number of modules implemented, the reasons for implementation, observed problems and realised advantages.

Implementation of a PDM system often is limited to a sub-set of its functions, like data vault and document management, parts' management, product structure management, and configuration management. In addition, a PDM system is mainly used by $\mathrm{R} \& \mathrm{D} /$ product development, production engineering and production. Purchase, maintenance/service, and marketing/sales are only incidentally involved. Advantages often mentioned are time and cost reduction in product development and increase in component reuse although the achieved advantages are not always as high as expected.

Several important conclusions have been drawn from the survey. Firstly, the enterprise-wide character of PDM is recognised, but not yet realised. Secondly, anticipation on problems that may occur during and after implementation is still insufficient. Thirdly, connection to the system by clients and suppliers is only realised when external pressure is high.

Our research is a first step towards formulating guidelines for implementing an enterprise-wide system like a PDM system. The research shows that many factors play a role, for a large part organisational, but also technical, during and after an implementation process. Our research has mainly focused on the organisational aspects.

We have presented an approach to plan, monitor, and improve PDM implementation and use. A rough outline of the factors considered important in this approach has been presented. Further research will refine this list of factors as well as the performance indicators that will play an important role. In the IST project BEST (Wognum et al., 2004), 24 case studies have been performed all over Europe to identify problems and their causes during an enterprise system implementation process. Results indicate specific organisational and technical problems with PDM implementation. An initial tool has been developed to support consultants in assessing a company with respect to its readiness for implementing an enterprise system. 


\section{Acknowledgement}

We thank Henk Jan Pels from the Technical University of Eindhoven and Remco Helms from University of Utrecht for their comments and advice during development of the survey.

\section{References}

Argyris, Ch. and Schön, D. (1978) Organizational Learning: A Theory of Action-perspective, Addison-Wesley, Reading, MA.

Bikson, T. and Gutek, B. (1984) Implementation of Office Automation, Rand Corporation, Santa Monica, CA.

Boer, H. (1991) Organising Innovative Manufacturing Systems, Avebury Academic Publishing Group, Aldershot, UK.

CIMdata (1995) Product Data Management: The Definition, An introduction to concepts, benefits, and terminology, CIMdata, Inc.

Crosby, P.B. (1979) Quality is Free: The Art of Making Quality Certain, McGraw-Hill, New York.

Davenport, T.H. (2000) Mission Critical. Realizing the Promise of Enterprise Systems, Harvard Business School Press, Boston, Massachusetts, USA.

During, W.E. (1986) Innovation Problems in Small Industries, PhD Thesis, University of Twente, Enschede, The Netherlands (in Dutch).

Engineering Data Management Newsletter (1999) Benefits of EDM/PDM in Manufacturing Industries, Vol. 9, No. 3, December, pp.3-6.

Engineering Data Management Newsletter (2000) UK PDM Survey, Vol. 9, No. 8, May, pp.5, 6.

Hamel, G. and Prahalad, C.K. (1994) Competing for the Future, Harvard Business School Press, USA.

Kerssens-van, D.I.C. (1999) Systematic Design of R\&D Performance Measurement Systems, $\mathrm{PhD}$ Thesis, University of Twente, The Netherlands.

KPMG (2002) Annual Program Management Survey 2002, Report 203-587, KPMG-LLP, UK.

Krabbendam, J.J. (1988) New Technologies and Organisational Measures. Flexible Manufacturing Systems in Practice, PhD Thesis, University of Twente, Enschede, The Netherlands (in Dutch).

Kwon, T.H. and Zmud, R.W. (1987) Unifying the Models of Information System Implementation. Critical Issues in Information System Research, John Wiley, New York.

Landauer, T.K. (1995) The Trouble with Computers: Usefulness, Usability and Productivity, MIT Press, Cambridge, MA.

Lange-Ros de, D.J. (1999) Continuous Improvement in Teams. The (mis)fit between Improvement and Operational Activities of Improvement Teams, $\mathrm{PhD}$ Thesis, University of Twente, Enschede, The Netherlands.

Leonard-Barton, D. (1988) 'Implementation as mutual adaptation of technology and organization', Research Policy, Vol. 17, pp.251-267.

Markus, M.L. and Tanis, C. (2000) 'The enterprise system experience: from adoption to success', in Zmud, R.W. (Ed.): Framing the Domains of IT Management: Projecting the Future Through the Past, Pinnaflex Educational Resources, Cincinnati, pp.173-207.

Nash, K.S. (2000) 'Companies don't learn from previous IT snafus', Computer World, October 30.

Orlikowski, W. (1992) 'The duality of technology: rethinking the concept of technology in organizations', Organization Science, Vol. 3, No. 3, pp.398-427.

Ruël, H. (2001) The Non-technical Side of Office Technology, PhD Thesis, University of Twente, Enschede, The Netherlands. 
Trist, E.L. and Bamford, K.W. (1951) 'Some social and psychological consequences of the longwall method of coal-getting', Human Relations, Vol. 4, pp.3-38.

Willcocks, L.P. and Lester, S. (1999) Beyond the IT Productivity Paradox, Wiley, Chichester.

Wognum, P.M. and Faber, E.C.C. (2002) 'Infrastructures for collaboration in virtual organisations', Int. J. Networking and Virtual Organisations, Vol. 1, No.1, pp.1-23.

Wognum, P.M. and Kerssens-van Drongelen, I.C. (2001) 'Process and impact of product data management implementation', in Roy, R. and Prasad, B. (Eds.): Proceedings of the8th ISPE International Conference on Concurrent Engineering, ISBN 0-9710461-0-7.

Wognum, P.M., Fisscher, O.A.M. and Weenink, S.A.J. (2001) 'Balanced relationships: management of client-supplier relationships in product development', Technovation, Vol. 22, pp.341-351.

Wognum, P.M., Mensink, G., Buhl, H., Ma, X., Sedmak-Wells, M. and Fan I.S. (2004) 'Collaborative enterprise system implementation. Improving project start-up', in Sobolewski, M. and Cha, J. (Eds.): Proceedings of the 11th International Conference on Concurrent Engineering - The Worldwide Engineering Grid, Tsinghua University Press, pp.583-588.

Yin, R.K. (1994) Case Study Research: Design and Methods, Sage Publications, Inc. 